\title{
The approximate method of determining the integral physical characteristics in some problems of technical theory of plates
}

\author{
Viktor Korobko, Natalia Kalashnikova and Stanislav Shlyakhov* \\ Orel State University named after I.S. Turgenev, Komsomolskaya str., 302026 Orel, 95, Russia
}

\begin{abstract}
The paper considers the dimensionless geometric characteristic $R / r(R$ is the maximum radius of a circle inscribed in a given region, $\mathrm{r}$ is the minimum radius of a circle circumscribed around it), which is used as a geometric analogue of integral characteristics in problems of the technical theory of plates and theory of elasticity. By numerical experiment the authors showed that using this characteristic as the only argument made it possible to approximate with one elementary function all the solutions for short plates, which satisfied the condition $(0.5<R / r<1)$ in problems of trans-verse bending, free oscillations and stability of plates.
\end{abstract}

\section{Introduction}

For the past $20 \ldots 25$ years, the scientific school in Orel technical university (now Orel State University named after I.S. Turgenev), headed by Professor V.I. Korobko, has been conducting active research in the development of geometric methods for solving the problems of the technical theory of elastic plates (transverse bending of plates, free oscillations, stability) and the theory of elasticity (the given geometric stiffness of cross sections of the twisting rod $i_{k}$ ).

Several effective engineering methods for solving these problems have been developed, among them: the isoperimetric method (ISPM) [1, 2], the method of interpolation by the form factor (MIFF) $[3, \ldots, 6]$, the method of interpolation with respect to the conformal radii (MIRCR) [7, 8]. Developing these methods, a functional relationship was established between the integral physical characteristics in the problems under consideration (maximal deflection $\mathrm{w}_{0}$, fundamental oscillation frequency $\omega$, critical force with loss of stability $N_{0}$ plates, the geometric stiffness given of the cross section of the twisting rod) with integral geometric parameters of the plates (form factor $K_{f}$, the ratio of conformal $\operatorname{radii} \dot{r} / r$ ). Detailed information on the form factor and its isoperimetric properties is presented in [1, $3,9]$. These methods make it possible to reduce the solution of complex physical problems to elementary geometric problems. In this case, the magnitude of the integral physical characteristics, their behavior under various geometric transformations of the contour of the given plates (sections) are judged by the magnitude and behavior of the integral geometric characteristics, which are described by elementary analytical dependences.

\footnotetext{
Corresponding author: sjs28@mail.ru
} 
In this paper, we investigate another geometric parameter - the ratio $R / r$ ( $R$ is the maximum radius of the circle inscribed in the given region of the plate, $\mathrm{r}$ is the minimum radius of the circle circumscribed around it). This parameter is very similar to the ratio of the conformal radii $\dot{r} / r$, but numerically for the same figure they differ with the exception of the circle $(R / r=\dot{r} / r=1)$. The advantage of the parameter $R / r$ is its simplicity.

\section{Methods}

When developing the methods mentioned in the introduction, a fundamental regularity was established:

- the entire set of values of the integral physical characteristics of plates with a convex contour and homogeneous boundary conditions (either hinged contour support or rigid pinching) $F$ in the problems under consideration, represented in the coordinate axes $F-K_{f}$, is bounded from two: elliptic plates form one of the boundaries $F$, and plates in the form of regular figures and isosceles triangles form the other one;

- for triangular and quadrangular plates, rectangular plates form one of the boundaries $F$, and plates in the form of regular figures and isosceles triangles form the other one.

This pattern is illustrated in Fig. 1. Fig. 1 (a) demonstrates the $K_{f}-R / r$ dependences, and Figure 1-b shows the dependence of the given geometric stiffness of the cross section with free torsion of the rod $i_{k}-K_{f}$. The graphs of the dependencies $w_{0}-1 / K_{f}, 1 / \omega-1 / K_{f}, N_{0}-$ $1 / K_{f}$ are similar to those shown in Fig. 1 (b).

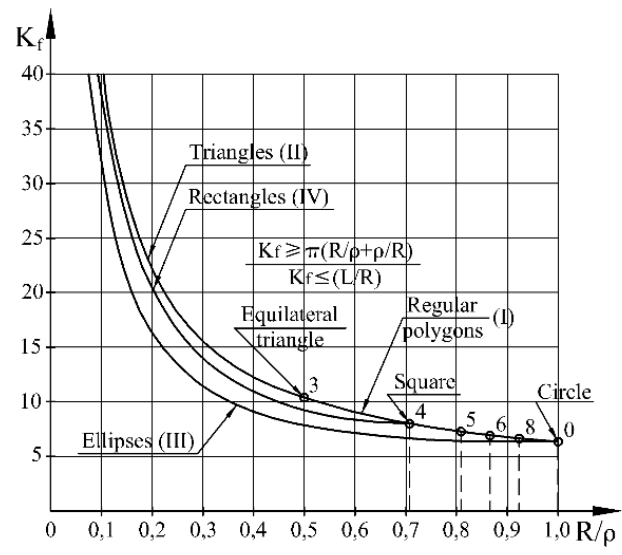

(a)

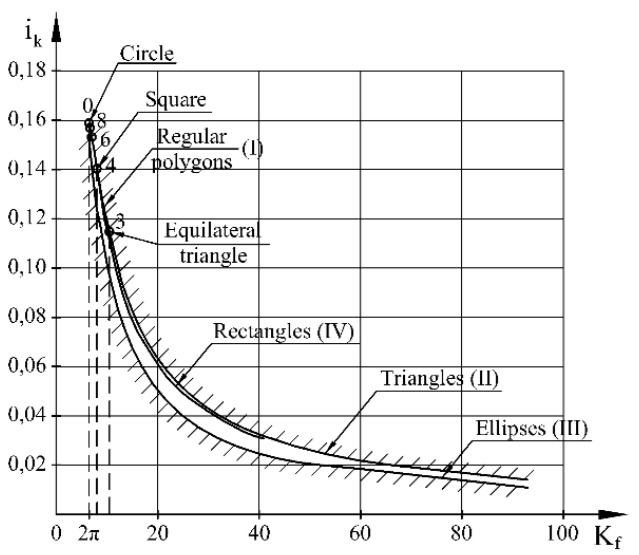

(b)

Fig. 1. Dependencies $K_{f}-R / r$ (a) and $i_{k}-K_{f}$ (b)

The analysis of these graphs suggests that in view of the very narrow range of the values of the integral physical characteristics for a subset of short plate forms that satisfy the condition $0,5 \leq R / r \leq 1$, all the curves presented can be approximated by a single function.

Let us consider the data given in Tables 1, 2, and 3. In these tables, column 4 presents known solutions to three problems: the determination of the maximum deflection during transverse bending of rigidly clamped plates, whose form is indicated in column 2 , by a uniformly distributed load (Table 1); the fundamental frequency of oscillations of rigidly bound plates in an unloaded state (Table 2); critical force with uniform compression of rigidly clamped plates (Table 3 ).

According to the data given in table 1, 2, 3 (columns 4), the approximating functions were constructed: 


$$
\begin{gathered}
w_{0}=\left[4.756 \cdot(R / r)-2.204 \cdot(R / r)^{2}-0.969\right] \mathrm{q} \cdot \mathrm{A}^{2} / \mathrm{D} ; \\
\omega=;\left[76.5982-89.7365 \cdot(R / r)+45.2183 \cdot(R / r)^{2}\right] / A \times \sqrt{D / m} ; \\
N_{0}=\left[131.669-176.205 \cdot(R / r)+91 \cdot(R / r)^{2}\right] \times D / A .
\end{gathered}
$$

Table 1. Comparison of known and approximate solutions in the problem of the maximum deflection of rigidly clamped plates

\begin{tabular}{|c|l|c|c|c|c|}
\hline No & The plate form & $R / r$ & $\begin{array}{c}\text { Known solutions } \\
w_{0}=K q \cdot A^{2} / D\end{array}$ & $\begin{array}{c}\text { Solutions according } \\
\text { to the formula }(1)\end{array}$ & $\begin{array}{c}\text { Difference, } \\
\%\end{array}$ \\
\hline 1 & Regular figures: & \multicolumn{5}{|c|}{} \\
\hline 1.1 & circle & 1 & 1.583 & 1.583 & 0 \\
\hline 1.2 & hexagon & 0.866 & 1.478 & 1.496 & -1.21 \\
\hline 1.3 & pentagon & 0.809 & 1.409 & 1.436 & -1.85 \\
\hline 1.4 & square & 0.707 & 1.261 & 1.291 & -2.27 \\
\hline 1.5 & triangle & 0.5 & 0.880 & 0.858 & +2.53 \\
\hline 2 & Ellipses: & 1 & 1.583 & 1.583 & 0 \\
\hline 2.1 & $a / b=1$ & 0.9 & 1.557 & 1.526 & +2.01 \\
\hline 2.2 & $a / b=1.1(1)$ & 0.8 & 1.472 & 1.425 & +3.24 \\
\hline 2.3 & $a / b=1.25$ & 0.7 & 1.320 & 1.280 & +3.07 \\
\hline 2.4 & $a / b=1.428$ & 0.6 & 1.109 & 1.091 & +1.63 \\
\hline 2.5 & $a / b=1.6(6)$ & 0.5 & 0.858 & 0.858 & 0 \\
\hline 2.6 & $a / b=2$ & \multicolumn{5}{|l}{} \\
\hline 3 & Rectangles: & 0.640 & 1.259 & 1.280 & -1.65 \\
\hline 3.1 & $a / b=1.20$ & 0.6 & 1.102 & 1.091 & 1.00 \\
\hline 3.2 & $a / b=1.3(3)$ &
\end{tabular}

Notices to data in table 1 :

1. $K$ values are increased by $10^{3}$ and reduced to a unit area.

2. $K$ values for elliptical plates are found from the formula $w_{0}=\frac{1}{6.2} \cdot \frac{1}{3 K_{f}^{2}-8^{2}} \cdot\left(8 / K_{f}\right)^{0.33}$, obtained in the monograph [1].

3. Known solutions are borrowed from the monograph [10].

4. The designations used in tables 1,2,3: $q$ - the intensity of the distributed load, $D$ - the flexural rigidity of the plate, $A$ - the area of the plate, $m$ - the mass of the unit area.

Table 2. Comparison of known and approximate solutions in the problem of the fundamental frequency of oscillations of plates with a rigidly clamped contour

\begin{tabular}{|c|l|c|c|c|c|}
\hline No & The plate form & $\mathrm{R} / \rho$ & $\begin{array}{c}\text { Known solutions } \\
\omega=\beta^{2} / A \cdot \sqrt{D / m}\end{array}$ & $\begin{array}{c}\text { Solutions according } \\
\text { to the formula }(2)\end{array}$ & $\begin{array}{c}\text { Difference, } \\
\%\end{array}$ \\
\hline 1 & Regular figures: & \multicolumn{5}{|c|}{} \\
\hline 1.1 & circle & 1 & 32.08 & 32.08 & 0 \\
\hline 1.2 & hexagon & 0.866 & 32.91 & 32.798 & +0.34 \\
\hline 1.3 & pentagon & 0.809 & 33.62 & 33.595 & +0.07 \\
\hline 1.4 & square & 0.707 & 35.72 & 35.718 & +0.005 \\
\hline 1.5 & triangle & 0.5 & 42.51 & 43.045 & -1.25 \\
\hline 2 & ellipse a/b=2 & 0.5 & 43.56 & 43.045 & +1.18 \\
\hline 3.1 & $\begin{array}{l}\text { rectangle } \\
\text { a/b }=1,5\end{array}$ & 0.56 & 40.37 & 40.72 & -0.85 \\
\hline
\end{tabular}

Notices to data in table 2:

1. The values of the frequency parameter $\beta^{2}$ are reduced to the unit area.

2. Known solutions are borrowed from the monograph [11]. 
Table 3. Comparison of known and approximate solutions in the problem of the stability of plates with a rigidly constrained contour

\begin{tabular}{|c|l|c|c|c|c|}
\hline No & The plate form & $R / r$ & $\begin{array}{c}\text { Known solutions } \\
N_{0}=K \times D / A\end{array}$ & $\begin{array}{c}\text { Solutions according } \\
\text { to the formula (3) }\end{array}$ & $\begin{array}{c}\text { Difference, } \\
\%\end{array}$ \\
\hline 1 & Ellipses: & \multicolumn{5}{|l|}{} \\
\hline 1.1 & $a / b=1$ (circle) & 1 & 46.464 & 46.464 & 0 \\
\hline 1.2 & $a / b=1,2$ & 0.833 & 48.104 & 48.026 & +0.16 \\
\hline 1.3 & $a / b=1,4$ & 0.714 & 51.943 & 52.236 & -0.56 \\
\hline 2 & Rectangles: & \multicolumn{5}{|l|}{} \\
\hline 2.1 & $a / b=1$ (square) & 0.707 & 52.605 & 52.578 & +0.05 \\
\hline 2.2 & $a / b=1,4$ & 0.58 & 58.572 & 60.012 & -2.39 \\
\hline 3 & Hexagon & 0.866 & 48.012 & 47.321 & +1.43 \\
\hline 4 & $\begin{array}{l}\text { Equilateral } \\
\text { triangle }\end{array}$ & 0.5 & 63.393 & 66.317 & -4.40 \\
\hline
\end{tabular}

Notices to data in table 3:

1 . The values of parameter $K$ are reduced to the unit area.

2. Known solutions are borrowed from the monograph [2].

\section{Results and discussion}

Using the known data about the problems of the theory of plates, which is presented in the scientific and reference literature, regression dependences (1), (2), (3) were constructed for plates with a rigidly clamped contour, and these dependences allow getting satisfactory results for plates of any shape in interval of the ratio $0.5<R / r<1$ using only one geometric parameter $R / r$. The error in the results obtained with these formulas $(2-3 \%)$ satisfies the requirements for engineering calculations.

\section{Conclusions}

In the present paper, the example of plates with a rigidly clamped contour shows the possibility of constructing approximate dependences that allow obtaining satisfactory estimates of the integral physical characteristics under consideration for a variety of plate forms located in the interval $0.5<R / r<1$. The proposed method can also be applied to plates with an hinged contour and is extended to other problems in the theory of elasticity and plasticity, in particular, free torsion of prismatic rods, transverse bending of plates on the elastic foundation, limiting state of plates in transverse bending. The presence of a simple analytic dependence for a certain set of plate forms greatly facilitates the solution of complex physical problems. Therefore, it is necessary to continue research in this scientific direction.

\section{References}

1. V.I. Korobko, Isoperimetric method of structural mechanics : theoretical basis of isoperimetric method (Publishing ASV, Moscow, 1997)

2. V.I. Korobko, A.N. Khustochkin, Isoperimetric method in plate stability problem (Publishing North Caucasian Scientific Centre of High Education, Rostov-upon-Don, 1994).

3. A.V. Korobko, Area form geometrical modelling in two-dimensional problems of theory elasticity (Publishing ASV, Moscow, 1999) 
4. V.I. Korobko, A.A. Aktuganov, Stroitelstvo i rekonstruktsiya, 1, 18 (2014)

5. V.I. Korobko, S.Yu. Savin, Stroitelstvo i rekonstruktsiya, 2, 33 (2013)

6. V.I. Korobko, A.V. Korobko, S.Yu. Savin, A.A. Chernyaev, J. of the Serbian Society for Computational Mechanics, 10, 46 (2016)

7. V.I. Korobko, S.Yu. Savin, I.A. Ivlev, Proc. International Conference on Industrial Engineering, 924 (2017)

8. A.A. Chernyaev, Stroitelnaya mehanika inzhenernyh konstruktsiy i sooruzheniy, 2, 63 (2012)

9. G. Polya, G. Sege, Isoperimetric inequalities in mathematical physics (KomKniga, Moscow, 2006)

10. S.P. Timoshenko, S. Vojnovskij-Kriger, Plates and Shells (Fizmatgiz, Moscow, 1963)

11. V.S. Gontkevich, Natural Vibrations of Plates and Shells (Naukova dumka, Kiev, 1964) 